\title{
Diatom assemblages in a reservoir sediment core track land-use changes in the watershed
}

\author{
Lauren A. Schroeder - Scott C. Martin • \\ G. Jay Kerns • Colleen E. McLean
}

Received: 11 July 2013/Accepted: 19 September 2015/Published online: 26 September 2015

(C) The Author(s) 2015. This article is published with open access at Springerlink.com

\begin{abstract}
Diatom assemblages in a 144-cm sediment core reliably chronicled watershed changes and modifications of a riverine water-source reservoir in northeastern Ohio (USA) between 1932 and 2005. Non-metric Multidimensional Scaling segregated diatom assemblages into six groups that correspond to known anthropogenic modifications in the watershed and reservoir: zone I (filling, 1932-1936), zone II (high farming activity, 1937-1949), zone III (declining farm activity and increased residential development, 1950-1976), zone IV (implementation of sewage bypass, 1977-1982), reduced development activity caused by economic recession, 1983-1993), zone VI (renewed population growth and construction of a dam extension, 1994-2005). Ten watershed and reservoir environmental variables (percent farmland, population, $\mathrm{pH}$, total alkalinity, total hardness,
\end{abstract}

Electronic supplementary material The online version of this article (doi:10.1007/s10933-015-9860-4) contains supplementary material, which is available to authorized users.

L. A. Schroeder $(\bowtie)$

Department of Biological Sciences, Youngstown State University, Youngstown, $\mathrm{OH} 44555$, USA

e-mail: laschroe@zoominternet.net

S. C. Martin

Department of Civil/Environmental and Chemical

Engineering, Youngstown State University, Youngstown,

OH 44555, USA

e-mail: scmartin@ysu.edu transparency, surface area, air temperature, export of suspended solids, total phosphorus) were significantly correlated with diatom aggregate distribution in ordination space. Changes in species composition, in concert with watershed and reservoir changes, implicated light, alkalinity, and littoral macrophyte development as the primary drivers of diatom aggregate structure and function. Diatom productivity did not track nutrient loading (TP) and was likely driven by factors other than nutrients. Each zone was defined by a distinct set of environmental variables that differed from all other zones. Thus, diatom aggregate structure likely was determined by a dynamic suite of factors in the watershed and reservoir that had differential effects on diatom aggregate structure through time.

Keywords Reservoir - Diatom - Watershed - Water quality $\cdot$ Anthropogenic impact $\cdot$ Sediment core

\footnotetext{
G. J. Kerns

Department of Mathematics and Statistics, Youngstown State University, Youngstown, $\mathrm{OH} 44555$, USA

e-mail: gkerns@ysu.edu

C. E. McLean

Department of Geological and Environmental Science, Youngstown State University, Youngstown, OH 44555, USA

e-mail: cemclean@ysu.edu
} 


\section{Introduction}

Riverine reservoirs provide many useful services including water for domestic and industrial use (Jørgensen et al. 2005). The value of these services depends on the quality of the impounded water. Initial water quality is determined by site conditions, i.e. geology, climate, hydrology and morphometry. Subsequently, water quality is subject to modification in response to changes in watershed land use. Unlike natural lakes, in which conditions prior to human impacts can serve as a benchmark for determining human impact on water quality (Bennion et al. 2011), reservoirs are usually constructed where watersheds have already been modified by human activities. Thus, reservoirs have no "pristine condition" as a reference for impairment. Reservoirs, from their inception, are subject to anthropogenic stresses. As a consequence, human activities in the watershed either improve or degrade the quality of the reservoir water by alleviating (Anderson et al. 2005) or intensifying stressors, respectively (Kędziora 2003). Stressors external to the watershed may also affect water quality adversely, and include airborne nutrients and pollutants (Woodridge et al. 2014; Larsen 2000) and perhaps climate warming (McGowan et al. 2012). Because the highest standards apply to water used for domestic purposes and recreation, reservoirs constructed to provide these services are the most susceptible to impairment. Initial geological conditions are relatively stable over the lifetime of most riverine reservoirs. Therefore, with the exception of processes like climate warming, the magnitude and rate of degradation depends in large part on watershed use.

Understanding the relationship between external stressors and water quality is necessary for effective lake and reservoir management (Battarbee and Bennion 2011). One way to identify these linkages is paleolimnological methods, often using diatom-based transfer functions to reconstruct past water chemistry and correlate such changes with shifts in land use, atmospheric deposition or climate (Smol 1992; Wolfe et al. 2001). Paleolimnological methods are powerful tools that have enhanced our understanding of ecological processes in lacustrine systems (Smol 1992, 2008; Battarbee 1999). There are, however, cases for which paleolimnology alone is inadequate to decipher linkages between watershed alterations and lacustrine ecological processes (Saros 2009). Recently there has been an appeal to integrate neo- and paleolimnological methods to discern relationships between watershed changes and ecological processes, and to use historical chemical data to validate paleolimnological results (Battarbee et al. 2005; Saros 2009; Cabecinha et al. 2009; Woodridge et al. 2014).

Numerous paleolimnological studies have documented the effects of watershed alterations on lake water quality (Battarbee and Bennion 2011), but there are relatively few such studies of reservoirs (Shotbolt et al. 2005) and fewer still that use both historical data and paleolimnological methods to relate watershed use to reservoir water quality and service. The paucity of paleolimnological studies on reservoirs exists, in part, because traditional radioisotope dating techniques may not apply, making it difficult to obtain accurate sediment chronologies. Reservoirs also display higher sediment accumulation rates and sediment disturbance, compared to natural lakes, and this may confound interpretation of geochemical indicators (Shotbolt et al. 2005, 2006; Filstrup et al. 2010; Winston et al. 2014). Nonetheless, several paleolimnological studies have related changes in watershed conditions to water quality in reservoirs (Serieyssol et al. 2009; Filstrup et al. 2010; Liu et al. 2011; CostaBöddeker et al. 2012; Winston et al. 2014; Woodridge et al. 2014).

We report the relationship among changes in watershed use, historical water chemistry data, and stratigraphic geochemistry and diatom assemblages in a sediment core from Meander Creek Reservoir (MCR). The aims of this study were to determine if (1) the reservoir sediments reliably record changes in water-column conditions, and (2) changes in diatom community structure and function correspond to known watershed use, physical alterations to the reservoir and historical water chemistry data.

\section{Study site}

Meander Creek Reservoir (Fig. 1) is the primary potable water source for 300,000 people in the Youngstown-Warren, Ohio metropolitan area. The reservoir and water treatment plant are managed by the Mahoning Valley Sanitary District (MVSD). The reservoir was first filled in January 1932. An inflatable dam extension was installed in 1995, adding $41 \mathrm{~cm}$ to the full reservoir depth. The reservoir, at 
Fig. 1 Meander Creek Reservoir and watershed, northeastern Ohio, USA. The core site was near the dam and is marked by an " $X$ ". The five sub-basins are designated by roman numerals

\section{Meander Creek Watershed}

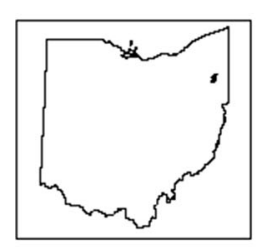

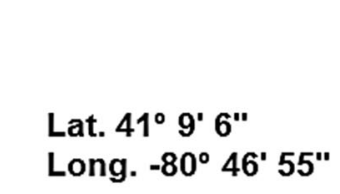

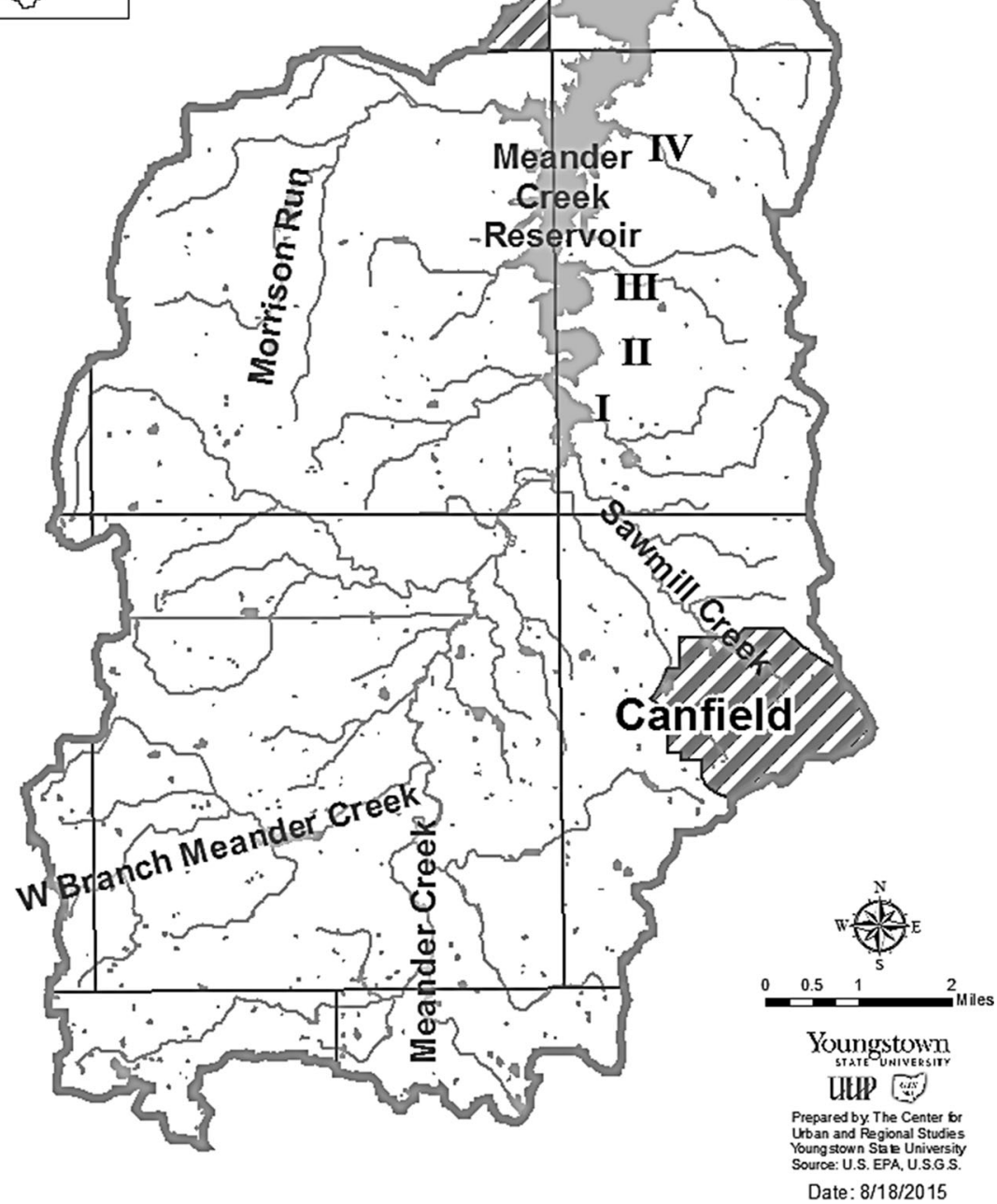

capacity, has a maximum depth of $15.7 \mathrm{~m}$, mean depth of $5.1 \mathrm{~m}$ and a watershed area of $221 \mathrm{~km}^{2}$. Prior to 1995, the reservoir covered $8.13 \mathrm{~km}^{2}$ and had a capacity of $37.8 \times 10^{6} \mathrm{~m}^{3}$. Since 1995 , with the dam extension, the reservoir area is $8.77 \mathrm{~km}^{2}$ and the volume is $42.5 \times 10^{6} \mathrm{~m}^{3}$, with a mean water residence time of 188 days. The north basin of the reservoir is dimictic, with a thermocline forming in May-June and breaking down in September-October. The land immediately around the reservoir (1600 ha) was planted in red pine (Pinus resinosa) and is a wildlife refuge that is closed to the public. The long, relatively narrow reservoir is constricted at four places, forming five sub-basins (Fig. 1).

Six historical modifications of the reservoir or watershed that may have affected diatom community structure and function were identified a priori: (1) the filling period was a time of rapid physical and chemical changes as the reservoir filled and stabilized (1932-1936); (2) non-mechanized farming dominated 
the watershed until the end of WWII (1937-1949); (3) following WWII, farmland decreased and population increased rapidly (1950-1976); (4) a sewage bypass, diverting sewage from the city of Canfield around MCR, was completed in 1977, marking the beginning of a period with sharply reduced nutrient loading (1977-1982); (5) on September 7, 1977 the steel industry in the Mahoning Valley began shutting down, initiating a sharp economic recession and population decline (1983-1993); (6) the local economy improved, leading to an increase in residential and commercial development in the MRC watershed, and a dam extension was added, increasing water volume and surface area (1994-2005).

\section{Materials and methods}

Sediment core

A 144-cm sediment core was collected with a piston corer in June 2005, near the center of the north basin $\left(41^{\circ} 9^{\prime} 4.23^{\prime \prime} \mathrm{N} ; 80^{\circ} 46^{\prime} 52.92^{\prime \prime} \mathrm{W}\right)$ in about $14 \mathrm{~m}$ of water (Fig. 1). Water above the surface sediment was removed with a pipette before sectioning. The core was cut into $1.12-\mathrm{cm}$ sections, a convenient increment for the extrusion device. The upper few centimeters of the core were unconsolidated and removed with a largebore pipette. Deeper sediments were sufficiently consolidated to be sliced and removed with a stainless steel knife. Sub-samples for diatom counts were taken from each section with a \#2 cork-borer (0.1-0.2 g wet weight), providing a sub-sample core of $3 \mathrm{~mm}$ diameter for the entire length of the core. Sub-samples for bulk density and pore water content were taken with a \#5 cork-borer $(2-3 \mathrm{~g})$ and placed in tared graduated centrifuge tubes and reweighed for bulk density determination. The sediment was centrifuged at $4000 \mathrm{~g}$ for $10 \mathrm{~min}$. Total volume was measured and the supernatant water (pore water) was removed with a pipette and weighed to $\pm 0.002 \mathrm{~g}$. The remaining sediment was weighed and dried at $105{ }^{\circ} \mathrm{C}$ for $24 \mathrm{~h}$ for determination of the dry mass. The dried material was ground with a mortar and pestle and stored in 20-ml glass scintillation vials. Sub-samples $(0.5-1 \mathrm{~g})$ of the dried material were combusted at $450{ }^{\circ} \mathrm{C}$ for $4 \mathrm{~h}$ to estimate organic matter content by weight loss on ignition (LOI).

Sub-samples for diatoms were cleaned by concentrated nitric acid digestion at $95{ }^{\circ} \mathrm{C}$ for $4 \mathrm{~h}$ and washed
5 times with DI water. The cleaned diatom suspension was diluted $1: 10$ and an aliquot of the diluted suspension was settled onto $22 \times 22-\mathrm{mm}$, number 1.5 glass cover slips and mounted in $\mathrm{ZRAX}^{\circledR}$. At least 400 diatom valves were counted, using an Olympus AO 70A microscope at $1000 \times$, along transects on the slide. Diatom identification was based primarily on the works of Hoffmann et al. (2011), Krammer and Lange-Bertalot (1986, 1988, 1991a, b), Houk (2003), Houk and Klee (2007), Houk et al. (2010) and Potapova (2010).

Because it was difficult to distinguish between some taxa, they were combined into aggregates. The Achnanthidium minutissimum species complex is difficult to separate with light microscopy (Potapova and Hamilton 2007) and was grouped as A. minutissimum agg. Most of the specimens were A. minutissimum (Kützing) Czarnecki var. minutissimum. Cyclotella bodanica agg. includes $C$. bodanica Eulenstein ex Grunow and Cyclotella radiosa (Grunow) Limmermann. Aulacoseira spp. is the sum of all Aulacoseira, excluding Aulacoseira pusilla (F. Meister) Tuji et Houki, Aulacoseira subarctica (O. Muller) Haworth and Aulacoseira granulata (Ehrenberg) Simonsen. Cyclotella spp. is the sum of all Cyclotella, excluding Cyclotella ocellata Pantocsek and $C$. bodanica agg. Fragilarioides is the sum of all Fragilarioides, excluding Fragilaria nanana and Fragilaria crotonensis Kitton. Only taxa that were identified to species, comprised at least $1 \%$ of the total counted valves, and occurred in at least three samples, were used for inferences of total phosphorus (TP). Aggregate taxa were included for ordination analysis.

Core chronology was determined from a combination of four time markers: core top (2005), core bottom (1932) and two ${ }^{137} \mathrm{Cs}$ dates. Cesium-137 analyses were carried out using gamma spectrometry at the $\mathrm{St}$ Croix Watershed Research Station, Science Museum of Minnesota, Marine on St. Croix, MN.

Historical water chemistry and physical data are from the records of the MVSD. These data include: $\mathrm{pH}$, total alkalinity (TALK), total hardness (HRD), turbidity, and reservoir surface area (A). Except for hydrological data, records from 1982 until 1994 were lost. Watershed land use data were derived from USDA NASS (2006), population data from the USA 10-year township census data, and the exports of TP and suspended solids (SS) were calculated from land use and respective export coefficients (ESM Table 1). 
Mean monthly air temperature data are from the Youngstown, Ohio weather station located about $10 \mathrm{~km}$ north of MCR (NOAA 2014). The environmental variables are expressed in relative terms as the percent of the maximum observed value, to facilitate comparisons among variables.

\section{Data and statistical analysis}

Each core section contained less than one year of deposition, thus seasonal variation in diatom productivity is not synchronized with core sections and, consequently, increases the variability in valve counts and assemblage composition. To compensate for this variability, valve counts were "smoothed" using the SPSS algorithm T4253. Total phosphorus reconstruction (DI-TP) was based on relative abundance $\left(\mathrm{RA}=\mathrm{X}_{\mathrm{ij}} / \sum \mathrm{X}_{\mathrm{ij}}\right.$, where $\mathrm{X}_{\mathrm{ij}}$ is the number of valves of taxon " $\mathrm{i}$ " in section " $\mathrm{j}$ "), using the European Diatom Data sets (EDDI, Juggins 2014 software and "combined TP" training set). Thirty-eight taxa met the criteria for inclusion in the fossil data set. Six regional North American (NA) training sets were considered along with the EDDI. The EDDI had the greatest concurrence with the MCR diatom taxa $(66 \%$ of eligible taxa in common) and the greatest inclusion of MCR valves ( $80 \%$ of all MCR valves included in the concurring taxa). The NA training sets that were considered were $50 \%$ or less in both concurrence and number of valves included. None of the NA sets included A. pusilla (syn. Aulacoseira subborealis) (Nygaard) Denys, Muylarert et Krammer, the most common diatom in MCR. The assumptions inherent in diatom-inferred reconstructions were not tested (Juggins et al. 2013), but DI-TP is consistent with measured values (winter 2000-2003, $p<0.05$ Oneway ANOVA), most of the eligible taxa were planktonic, which better meets the inherent assumptions than benthic species (Juggins et al. 2013), and for this study the trend in reconstructed values is more important than the absolute values.

Shannon-Weiner diversity $\left(\mathrm{H}^{\prime}\right)$ was determined using PCORD software (McCune and Mefford 1999). Non-metric multidimensional scaling (NMDS) was used to identify possible stratigraphic assemblage groups. Significance between groups was assessed with analysis of similarity software (ANOSIM) from the Pisces Community Analysis Package (CAP 2007). The NMDS ordination was fitted using the $R$
Statistical Environment (R Core Team 2012). Environmental variables were fitted to the ordination by the R package vegan (Oksanen et al. 2013). High multicollinearity was identified for farmland (F), SS and TP export, by way of fitting a redundancy analysis model, followed by variance inflation factor (VIF) measures for Canonical Correlation Analysis (CCA).

\section{Results}

Core geochemistry

The sediment was composed of uniform black gyttja. Herbaceous roots and mineral soil in the bottom segment indicated that the core extended through the entire reservoir sediment layer. Except for an anomalous decrease in percent dry matter content between 27 and $58 \mathrm{~cm}$, dry matter increased with depth, from $25 \%$ near the top to $50 \%$ near the bottom of the core (Fig. 2a). The increase in dry matter content is attributed to a decrease in porosity. Centrifuged pore water, a partial measure of porosity, decreased from $30 \%$ near the surface to $<8 \%$ in the deepest sediments (Fig. 2b). Fine silt and clay particles composed about $70 \%$ of the dry sediment from the surface to $60 \mathrm{~cm}$ and then decreased to $<30 \%$ by $105 \mathrm{~cm}$ depth (Fig. 2c). Organic content decreased from $7.5 \%$ in near-surface sediment to a low of $4.3 \%$ at $133 \mathrm{~cm}$, but then increased in the deepest sediment (Fig. $2 d)$. Bulk density $\left(\rho_{d}\right)(=M / V$ where: $M$ is dry mass and $\mathrm{V}$ is wet volume) increased with depth from $0.3 \mathrm{~g} \mathrm{~cm}^{-3}$ near the top of the core to $0.7 \mathrm{~g} \mathrm{~cm}^{-3}$ near the bottom (Fig. 2e). The increase in bulk density with depth in the core is consistent with reduced pore space, changing inorganic composition and decrease in organic content.

\section{Chronology}

The total time from reservoir filling until the core was taken, i.e. 1932-2005, was 73 yr. Cesium-137 activity established two additional time markers, undetectable activity at $114 \mathrm{~cm}(1950 \pm 2 \mathrm{yr})$ and peak activity at $92 \mathrm{~cm}(1963 \pm 3 \mathrm{yr})$ (Fig. 2f). The primary source for ${ }^{137} \mathrm{Cs}$ was above-ground testing of nuclear weapons. There were few tests prior to 1950 and testing peaked about 1963 . The total accumulated dry mass at the core site was $72.3 \mathrm{~g} \mathrm{~cm}^{-2}$. The ${ }^{137} \mathrm{Cs}$ dates 

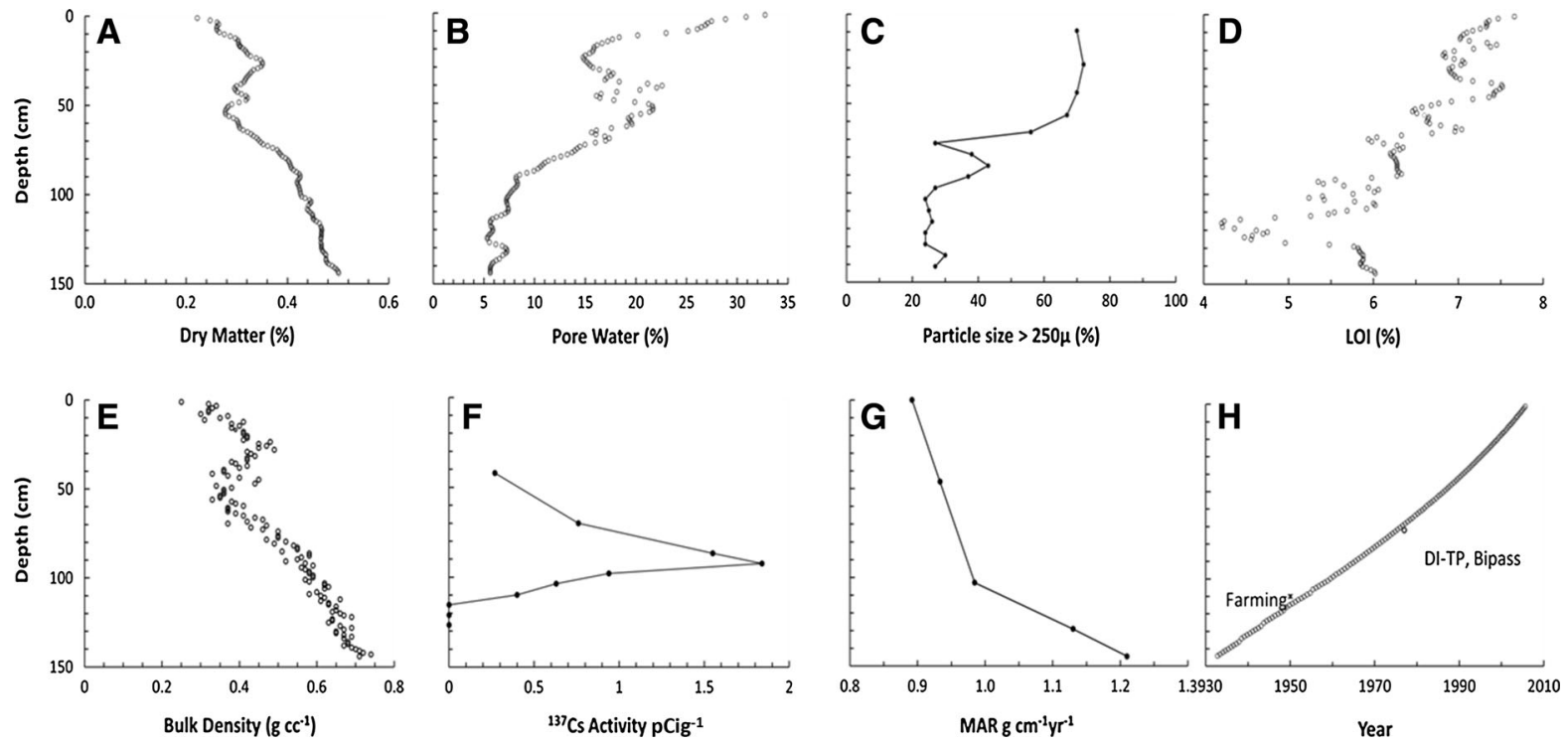

Fig. 2 Geochemical stratigraphy and chronology: a sediment dry matter $(\%)$; b pore water extracted by centrifugation (\% of wet sample mass); c particle size (particle size greater than $250 \mu \mathrm{m}, \%$ of total sample dry mass); $\mathbf{d}$ mass loss on ignition (\%); e bulk density; $\mathbf{f}^{137}$ Cs activity; $\mathbf{g}$ mean accumulation rate (MAR); h time-depth curve with two independently dated

divide the core into three segments: $144-115,115-92$, 92-0 cm, AD 1932-1950, 1951-1963 and

points- "o" marks the date when there is a sharp decrease in diatom-inferred total phosphorus, corresponding with the completion of the sewage bypass (1977); " $\mathrm{x}$ " marks the beginning of the rapid decline in farming (1950) and the beginning of the change in sediment grain size from coarse to fine material $(110 \mathrm{~cm})$

MAR $_{\mathrm{i}}=0.892+0.0009 *$ depth $_{\mathrm{i}} \mathrm{i}=1-104 \mathrm{~cm}$

1964-2005, respectively (Table 1). The mass accumulation rate (MAR) decreased toward the top of the core, from $1.13 \mathrm{~g} \mathrm{~cm}^{-2} \mathrm{yr}^{-1}$ in the deepest segments to $0.93 \mathrm{~g} \mathrm{~cm}^{-2} \mathrm{yr}^{-1}$ in the top segment (Table 1).

Linear interpolation of MAR on time from the midpoint of each segment provides an estimate of change in MAR with time (Eqs. 1, 2, Fig. 2g).

MAR $_{\mathrm{i}}=0.409+0.00557 * \operatorname{depth}_{\mathrm{i}} \mathrm{i}=104-144 \mathrm{~cm}$

A timeline was determined as the quotient of empirical sediment accumulation and $\mathrm{MAR}_{\mathrm{i}}$ (Eqs. 1 and 2) (Fig. $2 \mathrm{~g})$, where time $\left(\mathrm{yr} \mathrm{cm}^{-1}\right)=\rho_{\mathrm{di}} / \mathrm{MAR}_{\mathrm{i}}$. Calculation of sediment accumulation using Eqs. 1 and 2 provides a much better fit to the empirical data than using MAR. There is no significant difference between the empirical and calculated values for sediment accumulation $\left(\mathrm{g} \mathrm{cm}^{-2}\right)$ using a paired student $t$ test $(p>0.18)$.

Table 1 Dated core sections

\begin{tabular}{lcllll}
\hline Core section & Sediment depth $(\mathrm{cm})$ & Determined date & $\Delta$ Time $(\mathrm{yr})$ & $\Delta$ Sediment $\left(\mathrm{g} \mathrm{cm}^{-2}\right)$ & $\left.\mathrm{MAR}_{(\mathrm{g} \mathrm{cm}}^{-2} \mathrm{yr}^{-1}\right)$ \\
\hline 1 & 1 & 2005 & & & \\
82 & 92 & 1963 & 42 & 39.2 & 0.93 \\
102 & 114 & 1950 & 13 & 12.8 & 0.99 \\
129 & 144 & 1932 & 18 & 20.3 & 1.13 \\
\hline
\end{tabular}

Top 2005, bottom $1932 ;{ }^{137}$ Cs dates at Section 82 and $102 ; \Delta$ Sediment is the sediment accumulation in $\mathrm{g} \mathrm{cm}^{-2}$, MAR is the mean accumulation rate 
Diatoms

We measured six aspects of diatom assemblage structure and function: species present, relative abundance, productivity as the rate of valve accumulation, Shannon diversity index, relative abundance (RA) of planktonic taxa and RA of centric diatoms. All centric diatoms in MCR are considered to be planktonic. Of the 316 taxa present, the taxa or taxa aggregates that most notably contributed to the delineation of diatom assemblage zones are depicted in Fig. 3. Aulacoseira pusilla showed the highest relative abundance at $63 \%$. The RA of planktonic and centric taxa varied considerably, from 50 to $89 \%$ for all planktonic taxa and from 30 to $80 \%$ for centric taxa (Fig. 3). Planktonic diatom RA (all centric plus pennate plankton) is correlated significantly with reservoir surface area $(\mathrm{r}=0.522, p<0.002)$. Overall productivity ranged from 4 to 18 million valves $\mathrm{cm}^{-2} \mathrm{yr}^{-1}$ and Shannon diversity ranged from 2.2 to 2.85 (Fig. 3).

An a priori examination of changes in the watershed and the reservoir delineated six periods that may have caused detectable shifts in diatom assemblage composition: (1) filling of the reservoir and a short period of diatom colonization and establishment of macrophyte vegetation, (2) a stable period of high farming activity and low rural residential development until the end of WWII, (3) rapid decline in farming and a rapid increase in population following WWII, (4) construction of a sewage bypass from the city of Canfield around MCR, (5) economic downturn with the closing of the steel industry in the Mahoning Valley, and (6) construction of a dam extension, renewed economic activity and population growth. Each of these six watershed and reservoir events is associated with changes in diatom assemblage composition identified by NMDS analysis (Fig. 4). Each zone was significantly different from all others (pairwise comparison of all combinations gave a statistic score $\geq 0.914, p<0.001$ ) (ESM Table 2; ANOSIM, CAP software).

Zone I (1932-1937) is characterized by low total diatom production $\left(5.4 \times 10^{6} \pm 0.1\right.$ valves $\mathrm{cm}^{-2}$ $\mathrm{yr}^{-1}$ ), relatively low abundance of centric diatoms $(29 \pm 1 \%)$, a high total planktonic fraction $(87 \pm 3 \%)$ and a relatively low Shannon diversity index $\left(\mathrm{H}^{\prime}=2.5 \pm 0.1\right)$ (Fig. 3). The most abundant

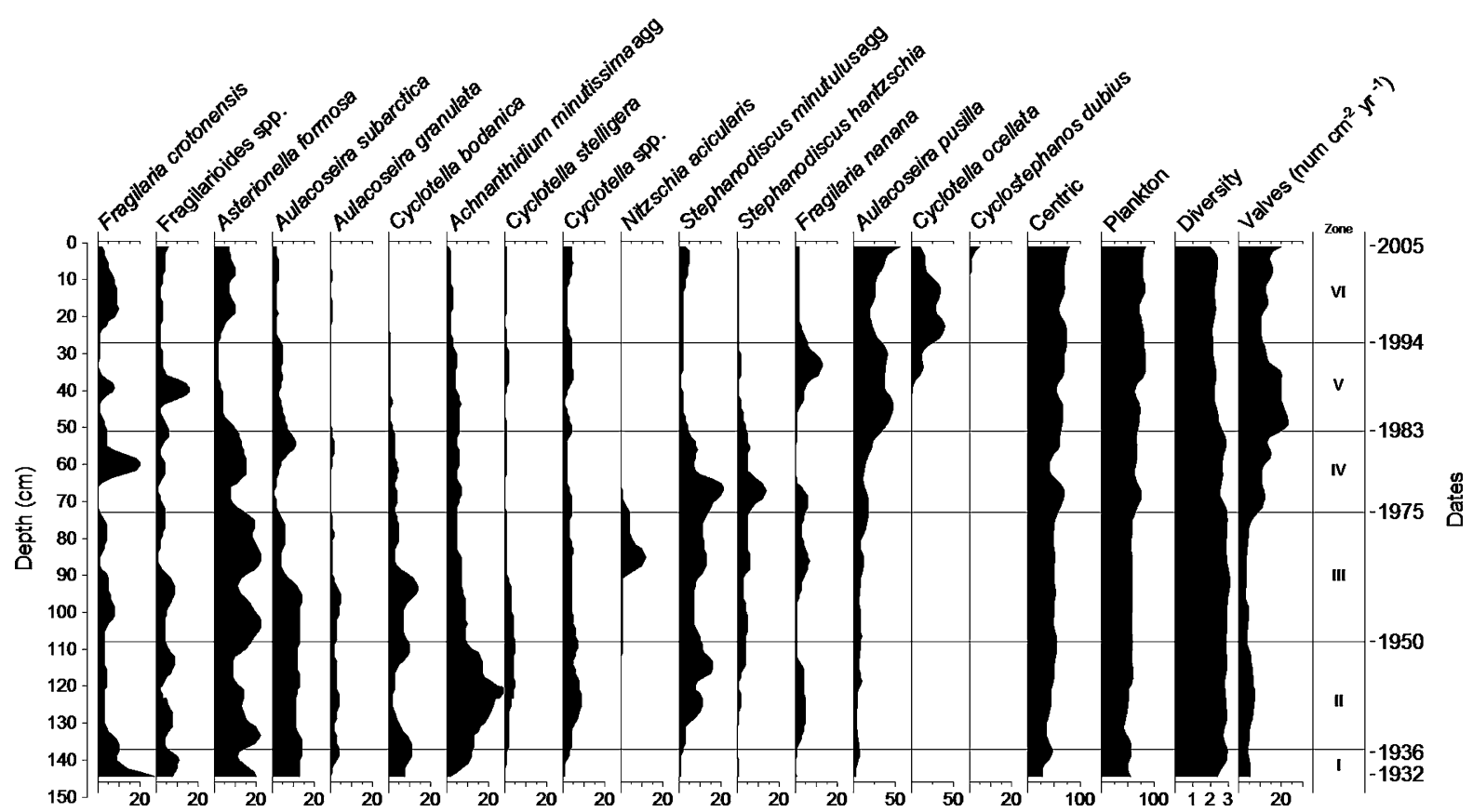

Fig. 3 Chronological distribution of common diatom taxa, all centric diatoms, all planktonic diatoms, Shannon diversity index $\left(\mathrm{H}^{\prime}\right)$ and diatom productivity (valves $\mathrm{cm}^{-2} \mathrm{yr}^{-1}$ ). All graphs except diversity and productivity are based on relative abundance (RA). Taxa are ordered from left to right corresponding to their importance in defining zones I-VI 


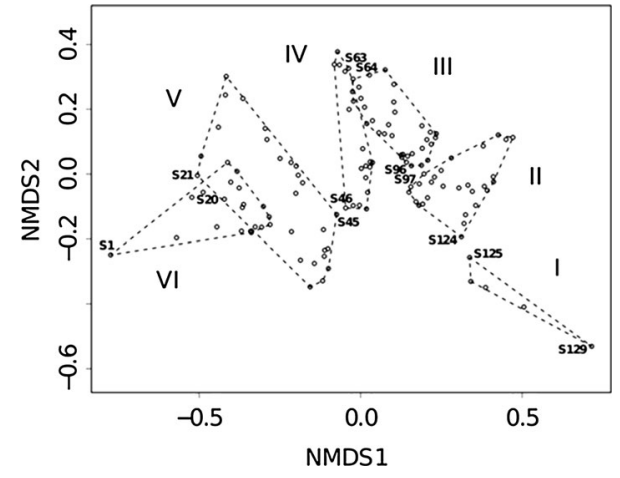

Fig. 4 Ordination graph for two-dimensional Non-Metric Multidimensional Scaling (NMDS) of diatom assemblages. Each data point represents a sediment section. Six groups (zones) were delineated and correspond to major watershed or reservoir events. The assemblage groups are sequential with the first and last section of each group labeled; S1 is the top core section, S129 the bottom section

taxa in zone I, accounting for $81 \%$ of the valves, were F. crotonensis $(23 \pm 8 \%)$, Asterionella formosa Hassall (19 $\pm 1 \%)$, Aulacoseira spp. (13 $\pm 1 \%)$, A. subarctica (O. Müller) Haworth $(10 \pm 3 \%)$, other Fragilarioides $(8.4 \pm 0.6)$ and $C$. bodanica Grunow $(7.8 \pm 0.1 \%)$.

Zone II (1937-1949) is characterized by continued relatively low productivity $\left(6 \pm 2 \times 10^{6}\right.$ valves $\mathrm{cm}^{-2}$ $\left.\mathrm{yr}^{-1}\right)$, high diversity $\left(\mathrm{H}^{\prime}=2.85 \pm 0.08\right)$ lower total planktonic RA $(75 \pm 4 \%)$ and relatively low, but increasing contribution of centric diatoms (Fig. 3). The mean RA of centric diatoms increased from $29 \pm 1 \%$ in zone I, to $48 \pm 5 \%$ (Fig. 3). Achnanthidium minutissimum agg. increased sharply to $17 \pm 5 \%$, accompanied by decreases in $F$. crotonensis $(5 \pm 3 \%)$, A. formosa $(14 \pm 4 \%)$ and A. subarctica (7士1\%) (Fig. 3). Aulacosiera granulata, $C$. stelligera Cleve \& Grunow, Stephanodiscus minutulus (Kützing) Cleve \& Möller and Cyclotella spp. were in relatively low concentrations, but attained near maximum RA in zone II.

Zone III (1950-1976) is characterized by relatively low diatom productivity $\left(4.5 \pm 1 \times 10^{6}\right.$ valves $\mathrm{cm}^{-2}$ $\left.\mathrm{yr}^{-1}\right)$, high diversity $\left(\mathrm{H}^{\prime}=2.95 \pm 0.08\right)$ and increased total planktonic forms $(84 \pm 1 \%)$ (Fig. 3). Asterionella formosa was the most common diatom $(18 \pm 3 \%)$, followed by A. pusilla $(10 \pm 3 \%)$ and $S$. minutulus agg. $(10 \pm 2 \%)$. Nitzschia acicularis Kützing \& W. Smith was nearly exclusive to zone III. A. subarctica and C. stelligera declined sharply near the mid-point of zone III.
Zone IV (1977-1982) is characterized by a marked increase in diatom productivity $\left(13 \pm 2 \times 10^{6}\right.$ valves $\left.\mathrm{cm}^{-2} \mathrm{yr}^{-1}\right)$, high but declining diversity $\left(\mathrm{H}^{\prime}=2.7 \pm 0.1\right)$, increasing RA of centric diatoms $(56 \pm 9 \%)$, and planktonic forms accounted for $86 \pm 2 \%$ of the diatoms (Fig. 3). A. pusilla $(18 \pm 5 \%)$ was the most common diatom followed by $S$. minutulus agg. $(12 \pm 6 \%)$ and A. formosa $(12 \pm 3 \%)$.

Zone V (1983-1993) is characterized by continued high diatom productivity $\left(18 \pm 4 \times 10^{6}\right.$ valves $\mathrm{cm}^{-2}$ $\left.\mathrm{yr}^{-1}\right)$ decreasing diversity $\left(\mathrm{H}^{\prime}=2.2 \pm 0.1\right)$, and increasing RA of centric diatoms $(66 \pm 7 \%)$. Total planktonic forms accounted for $86 \pm 2 \%$ of the diatoms (Fig. 3). The maximum RA of $F$. nanana occurred in zone V. Cyclotella ocellata Pantocsk $(7 \pm 8 \%$ ) first occurred in high numbers during zone V. Two species, A. pusilla $(40 \pm 4 \%)$ and $C$. ocellata, accounted for $47 \%$ of all valves in zone $\mathrm{V}$.

Zone VI (1994-2005) is similar to zone V in diversity $\left(\mathrm{H}^{\prime}=2.3 \pm 0.1\right)$ and centric diatoms $(69 \pm 5 \%)$, but differs in a decrease in productivity $\left(14 \pm 2 \times 10^{6}\right.$ valves $\left.\mathrm{cm}^{-2} \mathrm{yr}^{-1}\right)$, increase in all planktonic forms $(90 \pm 1 \%)$, the maximum and nearly exclusive occurrence of $C$. ocellata, and the first significant occurrence of Cyclostephanos dubius (Fricke) Round (Fig. 3). The most common taxon was A. pusilla (29 $\pm 9 \%)$, followed by C. ocellata $(27 \pm 9 \%)$ and A. formosa $(8 \pm 2 \%)$.

Environmental variables

\section{Watershed}

The initial fraction of the watershed in farmland was high $(70 \%)$ and remained high until after WWII (through zone II), declined to $40 \%$ by 1965 (zone III), then less rapidly to $<30 \%$ by 2005 (zone VI, Fig. 5a). As farming declined, the number of farms decreased even faster (Fig. 5b) resulting in fewer, but larger farms. This transition was likely driven by farm mechanization, as indicated by a $90 \%$ decrease in draft animals (Fig. 5c). With the decrease in draft animals, the land in pasture, hay and oats decreased (ESM Fig. 1). The first significant planting of soybeans occurred in the 1970s and increased rapidly to over $20 \%$ of the farmland by zone V (Fig. 5d). During the same period that farming was declining (zone III), the population 
increased by $3 \times(30 \%$ of maximum in 1948 to $90 \%$ of maximum by 1980) (Fig. 5e). Export of TP, similar to DI-TP, increased until 1977, when the bypass was opened, decreased through zone $\mathrm{V}$, and then increased to near maximum values in zone VI (Fig. 5g). The increase in TP export after installation of the sewage bypass is attributed to increased rural residential development and increased planting of soybeans. Productivity does not track nutrient concentrations, as measured by DI-TP or TP export (Fig. 5g). Productivity decreased through zone III, while TP export and DI-TP increased. Then, just prior to the bypass, it began to increase rapidly, attaining a maximum in 1986, 10 years after the peak TP values (Fig. 5g). Productivity and TP exhibit similar increases in zone VI.

Export of SS was high following reservoir filling, then declined with the decline in farmland (Fig. 5f). Unlike the export of TP, SS export did not increase during zone VI (Fig. 5f). The period of highest loadings of SS corresponds to the period of deposition of larger sediment particles (Fig. 2c), highest MAR (Fig. 2g) and non-mechanized farming activity.

\section{Reservoir chemical and physical properties}

The ranges in relative values for all variables except $\mathrm{pH}$, surface area and air temperature, were $>50 \%$ of the maximum value. The mean annual surface area of the reservoir had a range of about $20 \%$. The highest surface areas all occurred after the inflatable dam extension was installed in 1995 (Fig. 6a). Although the range in water surface area was relatively low, there was a significant trend toward larger surface area with time $\left(\mathrm{R}^{2}=0.075, \mathrm{~F}=10.36, p<0.002\right)$. Annual mean air temperatures tended to decline from $100 \%$ $\left(15^{\circ} \mathrm{C}\right)$ in zone I to $65 \%$ of maximum $\left(8.5^{\circ} \mathrm{C}\right)$ in zone III, then increased during the remainder of the study period (Fig. 6b). Secchi disk transparency (SD) increased steadily throughout the period, with the maximum occurring in zone IV and a range of $80 \%$ of the maximum (Fig. 6c). The pH was lowest in zone I, increased until zone III, and then decreased through zone VI. The range in $\mathrm{pH}$ was about $12 \%$ (Fig. 6d). Total alkalinity decreased sharply after filling to the minimum during zone II, then increased steadily through zone VI. The range for TALK was $55 \%$ (Fig. 6e). Total hardness increased from a minimum in
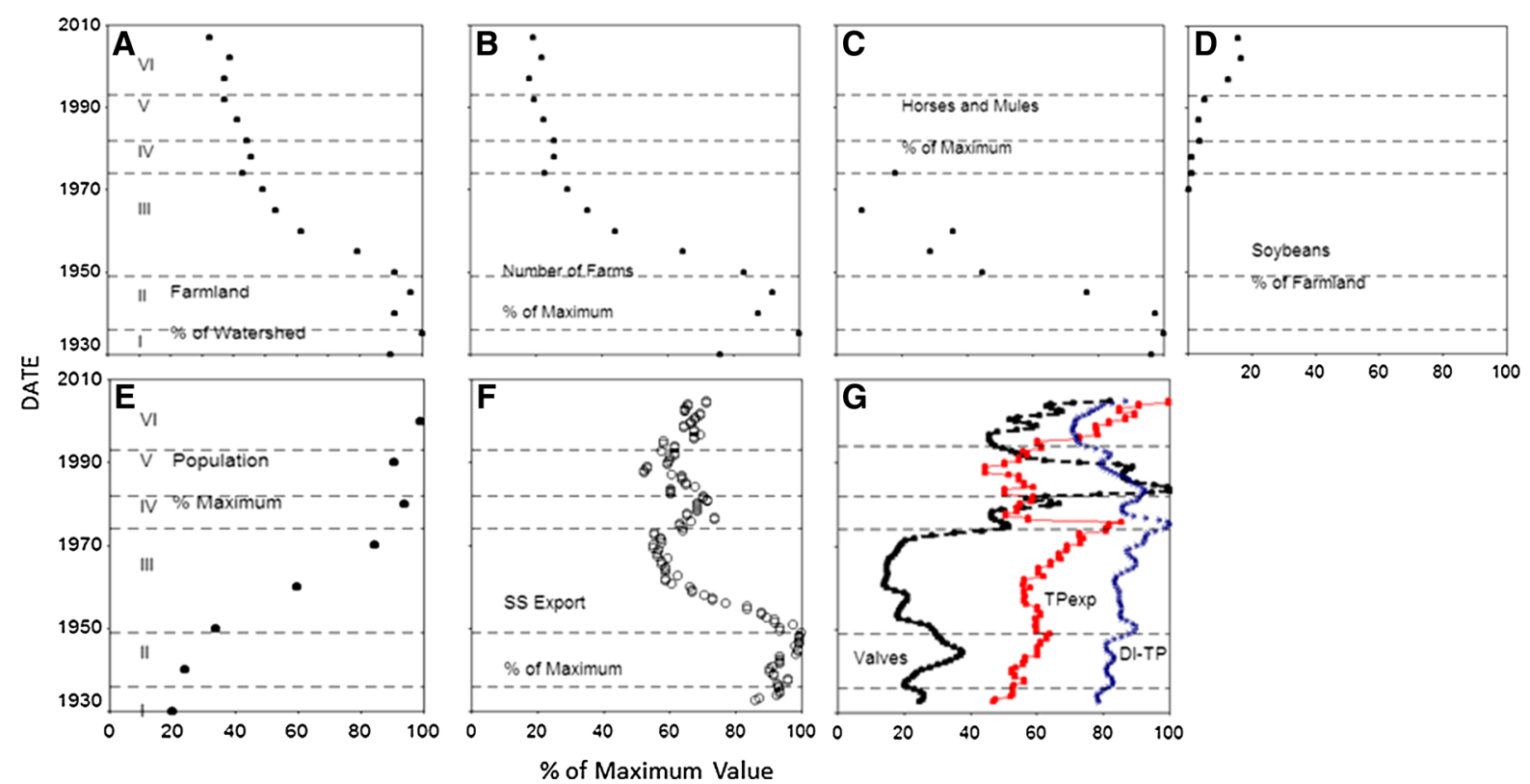

Fig. 5 Watershed environmental factors expressed as percent of maximum value for each variable $\left(\mathrm{X}_{\mathrm{j}}=100 \quad \mathrm{X}_{\mathrm{i}} / \mathrm{X}_{\mathrm{imax}}\right)$. Horizontal lines mark the boundaries of the diatom assemblage zones: a farmland; b number of farms; c draft animals; d soybeans; e population in the watershed (maximum 35,000); f calculated suspended solids export from the watershed; $\mathbf{g}$ black is \% of maximum of diatom valve deposition rate, red is \% of maximum total phosphorus exported from watershed and blue is $\%$ of maximum diatom inferred total phosphorus in the reservoir. (Color figure online) 
Fig. 6 Reservoir physical and chemical variables expressed as percent of maximum value. Horizontal lines mark the boundaries of the diatom assemblage zones: a surface area; b mean annual air temperature; c Secchi disk transparency; d pH; e total alkalinity; f total hardness
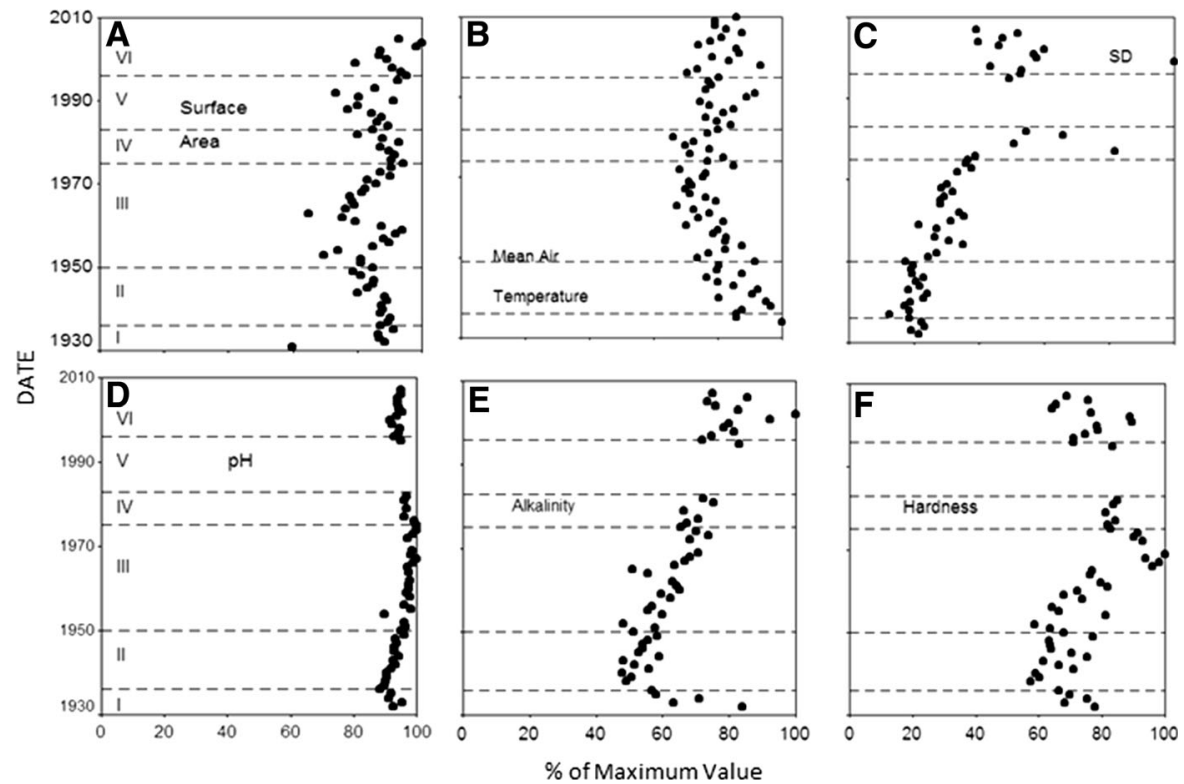

zone II to the maximum in zone III, and then declined until zone IV. The range was $40 \%$ of the maximum (Fig. 6f).

Diatom-inferred TP was low in the deepest sediment, and then trended higher to a maximum just after construction of the sewage bypass, then decreased rapidly to the lowest concentrations during the mid1990s (Fig. 5g). The validity of DI-TP computations was assessed by RMSE and Jackknife cross-validation weighted averaging, with inverse deshrinking. Performance statistics were: $\mathrm{RMSE}=0.298, \mathrm{R}^{2}=0.71$, ave. bias $=0.00$, max. bias $=0.62$. Jackknife errors of prediction were: $\mathrm{RMSE}=0.334, \mathrm{R}^{2}=0.637$, ave. bias $=0.00286$, max. bias $=0.719$. The mean measured TP concentration during the winters of 2000-2003 was $27 \pm 4 \mathrm{ppb}$ (Schroeder et al. 2009), which was similar to the DI-TP for the same period $(30 \pm 3 \mathrm{ppb})$.

\section{Biplots}

Biplots of variables in ordination space indicate strengths and potential correlations among variables (Fig. 7). All variables were highly significant $(p<0.001)$ in the overall discrimination of diatom assemblages (Table 2). Three groups of environmental variables showed similar vector directions: (1) hardness (HRD) and $\mathrm{pH}$; (2) farming (F), suspended solids (SS) and air temperature (T); and (3) population (P), Secchi disk transparency (SD), total phosphorus export (TP), total alkalinity (TALK) and reservoir surface area (A) (Fig. 7). Farmland, SS, and T are negatively correlated with P, SD, TP and TALK. Surface area is negatively correlated with HRD and $\mathrm{pH}$. Farming is inversely related to population (Fig. 7a).

Temporal changes in strengths of variables were assessed by NMDS analysis for each of the six zones (Fig. 7b-g). Each zone was distinct in the suite of variables that significantly accounted for the distribution of diatom assemblages (Table 2). No variable was significant across all zones (Table 2).

In zone I (Fig. 7, zone I), there were no significant variables at $p<0.01$ (Table 2). The absence of significant variables in zone I likely is attributed to the low number of diatom data points (four). In zone II (Fig. 7), all variables except TALK, HRD and SD were related to diatom assemblages (Table 2). Farmland (F), T and A were positively correlated, but negatively correlated with P, pH, TP and SS (Fig. 7, zone II). In zone III, all variables except $\mathrm{T}$ and SD were significant (Table 2). Total Alkalinity (TALK), pH, HRD, TP and P were positively correlated, but negatively correlated to SS and F (Fig. 7, zone I). Area (A) was significant, but not correlated with other variables. In zone IV, population (P), TALK, TP, $\mathrm{pH}$ and SD were significant $(p<0.01$, Table 2). Total phosphorus export and $\mathrm{pH}$ were positively correlated, but negatively correlated with $\mathrm{P}$ and SD (Fig. 7, zone I). Total alkalinity was significant, but not correlated with other variables. In zone V, because of missing records from 1980 until 1990, SD, TALK, $\mathrm{HRD}$, and $\mathrm{pH}$ were excluded from the NMDS analysis. 

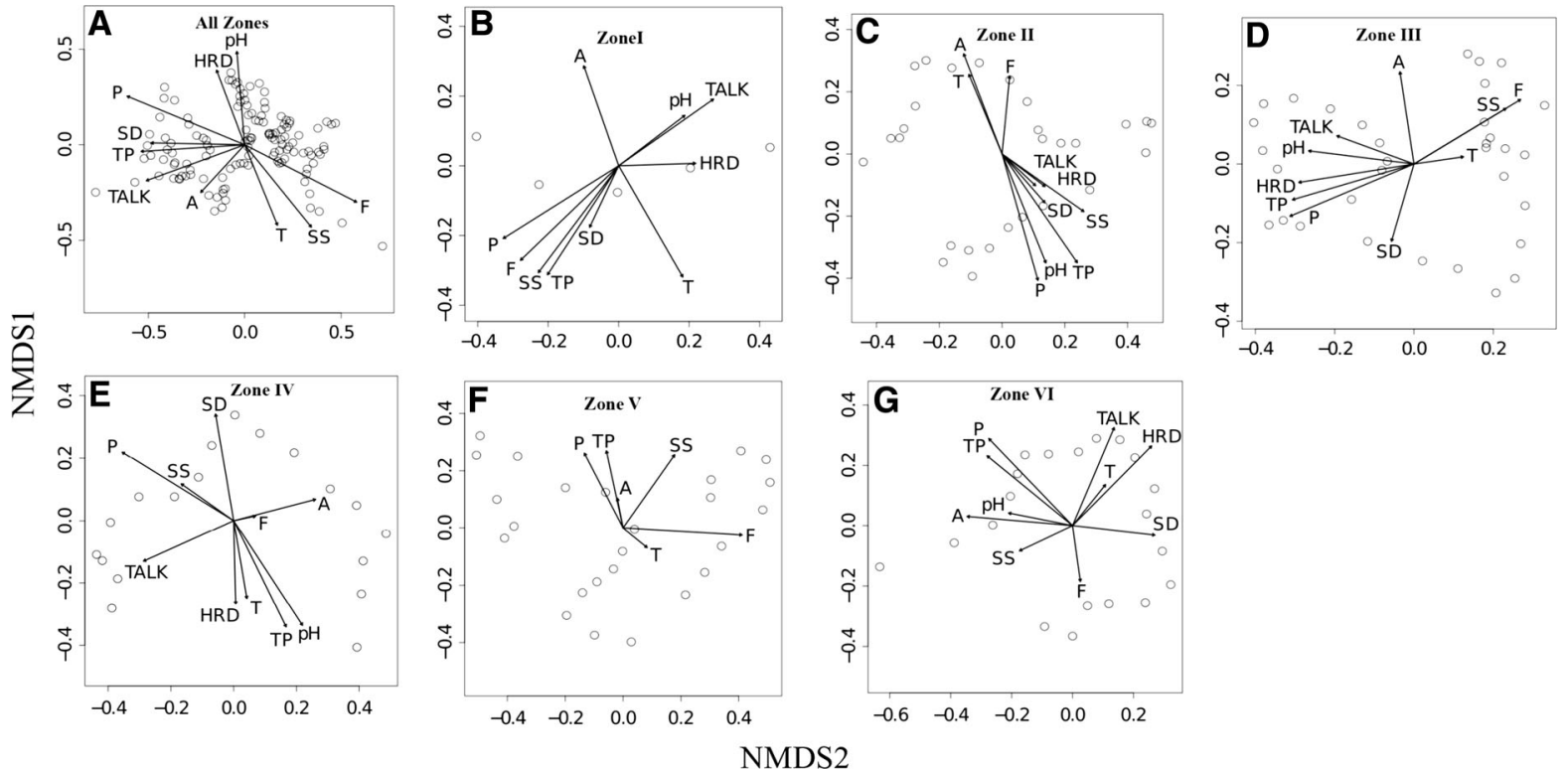

Fig. 7 Non-Metric Multidimensional Scaling (NMDS) ordination with environmental variable biplot vectors for all data (a) and for each diatom assemblage zone (b-g); P = population in the watershed, $\mathrm{F}=\%$ of watershed in farmland, $\mathrm{TP}=$ annual total phosphorus exported from the watershed, SS = annual total suspended solids exported from the watershed. MVSD data

for $\mathrm{pH}, \quad \mathrm{TALK}=$ total alkalinity, $\mathrm{HRD}=$ total hardness, $\mathrm{SD}=$ Secchi disk transparency, $\mathrm{A}=$ mean annual water surface area of the reservoir and $\mathrm{T}=$ mean annual air temperature. High values for NMDS1 correspond to older sediments, whereas low values are associated with recent deposition
Table 2 Significance of watershed and reservoir environmental variables in discriminating diatom assemblage distribution in NMDS ordination space by zones and combined (all zones)

$N S$ not significant,

$* p<0.05 ; * * p<0.01$; $* * * p<0.001$

\begin{tabular}{llllllll}
\hline Variable & \multicolumn{2}{l}{ Zones } & & & & & \\
\cline { 2 - 6 } & VI & V & IV & III & II & I & \\
\hline Farmland (F) & NS & $* * *$ & NS & $* * *$ & $* *$ & $*$ & $* * *$ \\
Population (P) & $* * *$ & $* *$ & $* * *$ & $* * *$ & $* * *$ & $*$ & $* * *$ \\
Total phosphorus export (TP) & $* * *$ & $* *$ & $* * *$ & $* * *$ & $* * *$ & $*$ & $* * *$ \\
Suspended solids export (SS) & NS & $* * *$ & NS & $* * *$ & $* * *$ & $*$ & $* * *$ \\
Air temperature & NS & NS & $*$ & NS & $* *$ & NS & $* * *$ \\
Surface area (A) & $* * *$ & NS & $*$ & $* *$ & $* * *$ & NS & $* * *$ \\
pH & NS & - & $* * *$ & $* * *$ & $* * *$ & NS & $* * *$ \\
Total alkalinity (TALK) & $* * *$ & - & $* *$ & $* *$ & NS & NS & $* * *$ \\
Total hardness (HRD) & $* * *$ & - & $*$ & $* * *$ & NS & NS & $* * *$ \\
Transparency (SD) & $*$ & - & $* *$ & $*$ & NS & NS & $* * *$ \\
\hline
\end{tabular}

All of the remaining variables except $\mathrm{A}$ and $\mathrm{T}$ were significant $(p<0.01$, Table 2). Population and TP were positively correlated, but uncorrelated with SS and F (Fig. 7). In zone VI the significant variables were A, TP, P, TALK and HRD ( $p<0.01$, Fig. 7). Population (P), TP and A were positively correlated; TALK and HRD were positively correlated, but uncorrelated with A (Fig. 7).

\section{Discussion}

Core validation

A variety of factors including water level fluctuation, density currents, and resuspension and focusing of sediments has fostered the perception that reservoir sediments are poor archives for watershed inputs 
(Shotbolt et al. 2005). This perception has restricted sediment core studies in reservoirs (Shotbolt et al. 2005; Filstrup et al. 2010; Winston et al. 2014). However, the distinct onset of ${ }^{137}$ Cs activity $(\sim 1950)$, the sharp ${ }^{137} \mathrm{Cs}$ peak (1963), consistency of the timeline with dated watershed events and the close correspondence of diatom assemblage composition with watershed events, confirm that MCR sediments are suitable archives for chronicling changes in the watershed.

\section{Environmental variables}

Except for installation of the sewage bypass and the addition of a dam extension, the other environmental variables displayed relatively gradual change. The discrete alterations are imbedded in more gradual changes in farming, population and watershed development. Thus, it is unlikely that changes in diatom RA would identify discrete boundaries of the differentiated diatom zones. We would expect more gradual shifts in RA and the zone boundaries would only be defined by changes in the aggregate structure analysis, but would not necessarily be apparent in a graphical analysis such as Fig. 3. Further support of the gradual effects of watershed factors is that the diatom aggregates form a trajectory in ordination space that corresponds to their position in the sediment core. Zone boundaries are further obscured by uncertainty in the chronology. Thus, the zone boundaries are fuzzier than depicted in Fig. 4. Nevertheless the discrete groups delineated by NMDS, and the significant correspondence of the groups with plausible driving factors, lend credence to the premise that changes in diatom aggregate structure are attributed to driving environmental factors in the watershed and in the reservoir. The zones form the basis for articulating specific testable hypotheses of cause and effect between watershed alterations and diatom community structure.

Diatom assemblage composition reflects the dynamic influence of temporally changing environmental variables. Within each zone, more than one environmental variable is correlated with diatom assemblage composition, and the set of correlated variables is different for each zone. Thus, chronological changes in diatom assemblages record changes in both the watershed and reservoir water chemistry. Some insight into which variables are most important in influencing diatom assemblage composition can be gleaned from the species composition and autecology of the common diatoms in each zone.

Periods of reservoir history

Zone I: reservoir formation (1932-1936)

Reservoirs typically undergo a flush in productivity, the "trophic upsurge," for a few years after filling. This is attributed to nutrient enrichment from the flooded soils and decomposition of inundated vegetation (Straškraba and Tundisi 1999; Baxter 1977). The upsurge, however, was not reflected in the diatom production in MCR. The "trophic upsurge" includes all producers, thus it may well have occurred in MCR, but diatoms did not participate. Although light is not a significant ordination variable, low light transmittance in zone I (mean Secchi disk $=0.9 \mathrm{~m}$ ) may have inhibited both diatom and other algal productivity.

Fragilaria crotonensis and A. formosa are planktonic pennate diatoms that are characteristic of zone I. They indicate anthropogenic disturbances (Wolin and Stoermer 2005), mesotrophic to eutrophic conditions (Stoermer and Smol 1999; Tilman and Kilham 1976), and are tolerant of low light conditions (Reynolds et al. 2002). Low light, absence of a mature littoral zone, and the suite of chemical and physical changes that occur during the formative period of reservoir development, likely are the primary variables that determined the diatom composition of zone I.

\section{Zone II: high farming activity (1937-1949)}

The transient conditions of zone I gave way to more stable diatom assemblages during the farming period, between 1937 and 1949. The diatom assemblage composition changed to include more small, singlecelled, centric diatoms that tend to grow faster, and therefore are more resistant to grazing pressures and out-wash (Reynolds et al. 2002). High abundance of the epiphytic diatom Achnanthidium minutissimum agg., during zone II, may have resulted from development of littoral macrophytes as the reservoir matured. Submerged macrophytes (Eurasian milfoil, Myriophyllum spicatum) covered $10 \%$ of the reservoir area in 1972 (Schroeder unpub.). Achnanthidium minutissimum is a ubiquitous benthic diatom that is common in waters with a wide range of alkalinity and 
trophic state conditions (Krammer and Lange-Bertalot 1991b), but is described as occurring in mesoeutrophic conditions by van Dam et al. (1994). Many members of the A. minutissimum complex are difficult to identify with light microscopy, and may have distinctive ecological requirements that are not often recognized in the literature (Potapova and Hamilton 2007). Asterionella formosa, the second most common diatom in zone II, is consistent with light-limiting conditions (Reynolds 1988). Stephanodiscus minutulus is a centric planktonic species characteristic of eutrophic conditions (van Dam et al. 1994). The diatom species composition and relatively low productivity, despite increasing DI-TP in zone II, are consistent with light limitation.

\section{Zone III: decreased farming and increased population (1950-1976)}

The likely driving factor for zone III is reduction in farming activity after WWII. The decline in farmland reduced both SS and TP loading, resulting in a significant increase in transparency. However, the reduction of TP export from farming is more than offset by the increase in TP from residential development. Thus, TP in the reservoir continued to increase, as indicated by increased DI-TP. The increase in centric diatoms is consistent with increased transparency (Saros and Anderson 2014). The increase in diversity is consistent with a deeper photic zone and increasing nutrient load from Canfield City sewage effluent. The common diatoms in zone III (A. formosa, $S$. minutulus, S. hantzschia and A. pusilla) all favor nutrient-rich environments (van Dam et al. 1994). A. pusilla is a widely distributed, but under-reported, colonial, planktonic diatom associated with more alkaline, eutrophic and turbid fresh waters. This is consistent with increasing alkalinity in MCR (Denys et al. 2003). Light remained low, consistent with continued low productivity.

\section{Zone IV: sewage bypass (1977-1982)}

The reduction in TP export, associated with completion of the bypass, marks the beginning of zone IV. The reduced TP export is also manifested by a sharp reduction in DI-TP. Contrary to the expected effects of reduced TP, productivity increased. This apparent anomaly may be attributed to relatively high and increasing transparency, forming a deeper photic stratum that overrode decreased nutrient levels. The increasing transparency resulted from reduced SS export and stabilization of the shore and littoral area from maturation of both the littoral zone macrophytes and pine planting around the reservoir. The increase in centric diatoms is attributed to a surge in abundance of A. pusilla, which was favored by increased alkalinity and hardness (Denys et al. 2003).

\section{Zone V: economic recession, reduced population (1983-1993)}

During zone V, much of the Mahoning Valley steel industry shut down, triggering a regional economic recession. Population growth in the watershed stalled, and even declined, resulting in a downturn in residential development that is reflected in reduced export of nutrients and SS. This was also the period when enforcement of the Clean Water Act was widely implemented, likely improving surface water quality and reducing pollution loading to the reservoir. Acid mine drainage from an abandoned coal strip mine in the watershed was also abated (USEPA 1971). Common diatoms are $A$. pusilla and the first substantial occurrence of $C$. ocellata. Reduction in nutrient and SS loading from reduced development of the watershed is reflected in lower DI-TP and higher transparency. This is consistent with increased abundance of centric diatoms and mesotrophic water conditions. The increase in $C$. ocellata, a centric alkaliphilous unicellular planktonic diatom, is consistent with increased alkalinity (Padisak et al. 2009; van Dam et al. 1994).

\section{Zone VI: renewed population growth and dam extension (1994-2005)}

Zone VI began with the construction of a $41-\mathrm{cm}$ dam extension. The subsequent increase in water level resulted in an increase in the pelagic proportion of the reservoir and should have caused a corresponding increase in planktonic versus non-planktonic diatoms (Soballe and Kimmel 1987). This premise is supported by the significant positive correlation between planktonic diatom RA and reservoir surface area. Concurrent with the dam extension, there was renewed population growth and an implied increase in construction in the watershed. During the latter part of 
zone VI, the MVSD occasionally treated MCR with copper sulfate to control Ceratium and Dynobryon (M. Kielbasa pers. commun.). Primary diatoms of zone VI are: C. ocellata, A. pusilla and Cyclostephanos dubius, the latter an alkaliphilous, planktonic, centric diatom favored by nutrient-enriched water (Clarke 1989; van Dam et al. 1994). Although C. dubius is a minor component of the diatom assemblages, it rapidly increased, exceeding $20 \%$ RA by the end of zone VI. Prior to $1985, C$. dubius was rare, occurring at $<1 \%$ in only a few older sediment samples. Its increase is consistent with continued increase in alkalinity and nutrient loading from residential population growth. C. dubius has high TP optima and is generally considered an indicator of eutrophic conditions. However, the ratio and levels of $\mathrm{NO}^{-3}$ and $\mathrm{NO}^{-2}$ may be more important than TP in determining $C$. dubius abundance (Bradshaw and Anderson 2003). The high and increasing DI-TP in zone VI may be an artifact of $C$. dubius populations that were responding to changing $\mathrm{NO}_{3} / \mathrm{NO}_{2}$ rather than TP.

Although diatom assemblage groups correspond to definitive events in the watershed and reservoir, they do not necessarily identify cause and effect relationships. Also, there were other factors that were not monitored, but may have impacted biota in the reservoir and contributed to the observed changes in diatom assemblage structure. In addition to coal mining and copper sulfate treatment mentioned above, unexplored factors include: expanded construction of highway infrastructure beginning about 1945, implementation of the Clean Water Act (1970s), increased use of salt as a road deicer after WWII, increased use of herbicides for weed control in crop lands beginning in the 1950s, deposition of airborne toxins from industry, stream bank erosion, grazing predation, disease, parasitism and allelopathy. All these factors, in addition to the ten monitored variables, potentially impacted diatom community structure in MCR.

\section{Diatom productivity and diversity}

The increases in LOI and diatom valve abundance are consistent with increased productivity through time. Most of the increase in productivity is attributed to an increase in the planktonic diatoms. This is consistent with increased plankton habitat caused by the addition of the dam extension (zone VI) and increased transparency (zone III and IV).
The Secchi disk transparency increased from $\sim 1 \mathrm{~m}$ after filling, to $>2 \mathrm{~m}$ by zone VI, indicating a near doubling of the volume of water in the photic zone. The correspondence between productivity and transparency in MCR is consistent with light being a common limiting factor for algal growth in reservoirs (Kimmel et al. 1990; Bradbury and van Metre 1997).

The disconnect between TP (TP export and DI-TP) and productivity (zone IV) is consistent with the premise that diatoms in MCR are not limited by nutrients, at least not by TP, but rather by other factors. The high early SS loading from farm activity (zone II) reduced transparency and kept productivity low, despite adequate nutrient concentrations. Then, as transparency increased (zone III), productivity increased even during the period following installation of the bypass (zone IV), when both TP export and DITP were relatively low. The close correspondence between TP export and DI-TP suggests that, although diatoms are not limited by TP, the composition of the diatom aggregates is TP-sensitive and tracks TP concentrations. That is, community species composition is in part determined by $\mathrm{TP}$, but productivity is limited by light or other factors. Increased light penetration may have enabled more effective use of nutrients, which increased diatom productivity and caused changes in diatom species composition, particularly the late occurrence of $C$. ocellata and $C$. dubius. Both A. pusilla and C. ocellata increased sharply in the more recent sediments, contributing to the surge in productivity and the concurrent decrease in the Shannon diversity index.

Both diversity and biomass of diatoms increased during the filling zone, attaining a stable value after about four years. During zone II, Shannon diversity was relatively high, consistent with resource limitation that suppressed the growth of all diatoms, reducing competition and preventing competitive release and dominance by a few taxa. Increased transparency during zone IV (1977-1982) was then exploited by diatoms in general, but most effectively by $C$. ocellata and A. pusilla. The high biomass of these two species is consistent with competitive suppression of other taxa, resulting in lower diatom diversity in the recent sediments. The pattern of decreasing diversity with relaxation of limiting factors, as MCR matured, is consistent with the inverse relationship between limiting factors and diversity observed in planktonic 
communities in mountain lakes of the western USA (Interlandi and Kilha 2001).

\section{Conclusions}

The combination of long-term chemical monitoring and sediment core diatom analysis provided reliable insights into the effects of watershed and reservoir modification on water quality in MCR. Meander Creek Reservoir, upon construction, was a resource-limited system. Benthic and epiphytic diatoms were limited by space and all diatoms were limited by light. As the littoral macrophyte community developed and shoreline erosion diminished, space limitation for benthic and epiphytic diatoms was relaxed and the fraction of these diatoms, especially A. minutissimum, increased. However, productivity remained low and did not follow the expected trophic state development trajectory (oligotrophic-mesotrophic-eutrophic), probably because of high turbidity during the years immediately following construction. Diatom productivity also did not track changes in nutrients (TP), inferred from diatom assemblages or calculated as watershed export. With time, changes in land use, water demand, reservoir morphometry, and sewage bypass construction relaxed the limiting factors (principally light, but also $\mathrm{pH}$, alkalinity, and hardness). As these factors were relaxed, species composition and species RA changed, resulting in increased productivity and reduced Shannon diversity index. The suite of effective limiting factors changed with watershed use and reservoir structure, resulting in a unique set of environmental factors being associated with each unique set of diatom assemblages (zones).

Acknowledgments Dr. Gary Walker, Department of Biological Sciences, YSU, gave valuable advice on microscopy and microphotography and permitted use of his darkroom and darkroom facilities. Dr. Carl Johnston, YSU, provided access to the microscope. We appreciate Eduardo Morales, Curator of the Cryptogamic Herbarium, Bolivian Catholic University, Cochabamba, Bolivia, for his patient help with diatom identifications. Carl Leet III, YSU Media Center, provided resources and help with digitizing of the film negatives and advice on microphotography. John Bralich, Center for Urban Studies, YSU, provided census data and the MCR map. Ellen Wakefield, YSU Maag Library, helped track literature sources. Tom Holloway, Superintendent, and Martin Kielbasa of the MVSD provided access to MVSD data and logistical support for fieldwork. Dr. Dan Engstrom provided ${ }^{137} \mathrm{Cs}$ analysis. Funding was provided by the MVSD and
Youngstown State University Research Council, Grant Number 2004-2005 \#1. We are especially indebted to two anonymous reviewers and the editor of JOPL for their patience and constructive criticisms of early versions of the manuscript.

Open Access This article is distributed under the terms of the Creative Commons Attribution 4.0 International License (http:// creativecommons.org/licenses/by/4.0/), which permits unrestricted use, distribution, and reproduction in any medium, provided you give appropriate credit to the original author(s) and the source, provide a link to the Creative Commons license, and indicate if changes were made.

\section{References}

Anderson N, Jeppesen E, Sondergaard M (2005) Ecological effects of reduced nutrient loading (oligotrophication) on lakes: an introduction. Freshw Biol 50:1589-1593

Battarbee RW (1999) The importance of paleolimnology to lake restoration. Hydrobiologia 395-396:149-159

Battarbee R, Bennion H (2011) Paleolimnology and its developing role in assessing the history and extent of human impact on lake systems. J Paleolimnol 45:399-404

Battarbee RW, Anderson NJ, Jeppesen E, Leavitt PR (2005) Combining paleolimnological methods and limnological approaches in assessing lake ecosystem response to nutrient reduction. Freshw Biol 50:1772-1780

Baxter RM (1977) Environmental effects of dams and impoundments. Annu Rev Ecol Syst 8:255-283

Bennion H, Battarbee R (2007) The European water framework directive: opportunities for paleolimnology. J Paleolimnol 38:285-295

Bennion H, Battarbee RW, Sayer CD, Simpson GL, Davidson TA (2011) Defining reference conditions and restoration targets for lake ecosystems using paleolimnology: a synthesis. J Paleolimnol 45:533-544

Bradbury JP, Van Metre PC (1997) A land-use and waterquality history of White Rock Lake reservoir, Dallas, Texas, based on paleolimnological analysis. J Paleolimnol 17:227-237

Bradshaw EG, Anderson NJ (2003) Environmental factors that control the abundance of Cyclostephanos dubius (Bacillariophyceae) in Danish lakes, from seasonal to century scale. Eur J Phycol 38:265-276

Cabecinha E, Cortes R, Cabral JA, Ferreira T, Lourenço M, Pardal MÂ (2009) Multi-scale approach using phytoplankton as a first step towards the definition of the ecological status of reservoirs. Ecol Indic 9:240-255

CAP (2007) Community analysis package 4 . Pisces Conservation Ltd. http://www.pisces-conservation.com/

Clarke K (1989) The distribution of Cyclostephanos dubius in Norfolk. Diatom Res 4:207-215

Costa-Böddeker S, Bennion H, de Jesus TA, Albuquerque ALS, Figueira RCL, Bicudo DD (2012) Paleolimnology inferred eutrophication of a shallow, tropical, urban reservoir in southeast Brazil. J Paleolimnol 48:751-766

Denys L, Muylaert K, Krammer K, Joosten T, Reid M, Rioual P (2003) subborealis stat. nov. (Bacillariophyceae): a 
common but neglected phytoplankton diatom. Nova Hedwigia 77(3-4):407-427

Filstrup CT, Scott JT, White DJ, Lind OT (2010) Use of element and isotopic comparisons to record the eutrophication of a polymictic reservoir in central Texas, USA. Lake Reserv Manag 15:25-39

Hoffmann G, Werum M, Lange-Bertalot H (2011) Diatomeen im Süsswasser-Benthos von Mittleuropa. A.R.G Ganter Verlag Kommanditgesellschaft, Ruggell

Houk V (2003) Atlas of freshwater centric diatoms with a brief key and descriptions. Part I. Melosiraceae, Orthosiraceae, Paraliaceae and Aulaoseiraceae. Czech Phycology Society, Benatska, Praha

Houk V, Klee R (2007) Atlas of freshwater centric diatoms with a brief key and descriptions. Part II Melosiraceae and Aulacoseiaceae (Supplement to Part I). Fottea Olomouc 7:85-255

Houk V, Klee R, Tanaka H (2010) Atlas of freshwater centric diatoms with a brief key and descriptions. Part III Part III Stephanodiscaceae. A. Fottea. Acad Sci Czech Repub 10(Supplement):1-498

Interlandi S, Kilha S (2001) limiting resources and the regulation of diversity in phytoplankton communities. Ecology 82:1270-1282

Jørgensen SE, Löffler H, Rast W, Straškraba M (2005) Lake and reservoir management. Elsevier, Amsterdam

Juggins S (2014) European diatom database. http://craticula.ncl. ac/Eddi/jsp/index.jsp. Accessed on 1 Feb 08-15 June 08

Juggins S, Anderson NJ, Ramstack Hobbs JM, Heathcote AJ (2013) Reconstructing epilimnetic total phosphorus using diatoms: statistical and ecological constraints. J Paleolimnol 49:373-390

Kędziora R (2003) Threats to and deterioration of small water reservoirs located within Wyskoć catchment. Polish J Environ Studies 12:567-573

Kimmel BL, Lind OT, Paulson LJ (1990) Reservoir primary productivity. In: Thornton KW, Kimmel BL, Payne FE (eds) Reservoir limnology. Wiley, New York, p 246

Krammer K, Lange-Bertalot H (1986) Bacillariophyceae. 1. Teil: Naviculaceae. In: Ettl H, Gerloff J, Heynig H, Mollenhauer D (eds) Süsswasserflora von Mitteleuropa, vol 2(1). Fisher Verlag, Jena

Krammer K, Lange-Bertalot H (1988) Bacillariophyceae. 2. Teil: Bacillariaceae, Epithemiaceae, Surirellaceae. In: Ettl H, Gerloff J, Heynig H, Mollenhauer D (eds) Süsswasserflora von Mitteleuropa, vol 2(2). Fisher Verlag, Stuttgart

Krammer K, Lange-Bertalot H (1991a) Bacillariophyceae. 3. Teil: Centrales, Fragilariaceae, Eunotiaceae. In: Ettl H, Gerloff J, Heynig H, Mollenhauer D (eds) Süsswasserflora von Mitteleuropa, vol 2(3). Fisher Verlag, Jena

Krammer K, Lange-Bertalot H (1991b) Bacillariophyceae. 4. Teil: Achnanthaceae. Kritische Ergänzungen zu Navicula (Lineolatae) und Gomphonema. In Ettl H, Gerloff J, Heynig H, Mollenhauer D (eds) Süsswasserflora von Mitteleuropa, vol 2(4). Fisher Verlag, Jena

Larsen J (2000) Recent changes in diatom-inferred pH, heavy metals, and spheroidal carbonaceous particles in lake sediments near an oil refinery at Mongstad, western Norway. J Paleolimnol 23:343-363
Liu J, Lin Z, Zhang H, Han B-P (2011) Hydrodynamic change recorded by diatoms in sediments of Liuxihe Reservoir, southern China. J Paleolimnol 47:17-27

McCune B, Mefford MJ (1999) PC-ORD. Multivariate analysis of ecological data, Version 4. MJM Software Design, Gleneden Beach

McGowan S, Barker P, Haworth E, Leavitt P, Maberly S, Pates J (2012) Humans and climate as drivers of algal community change in Windermere since 1850. Freshw Biol 57:260-277

NOAA (2014) National Oceanic and Atmospheric Administration. http://www.ncdc.noaa.gov/cag/timeseries. Accessed on Aug 2014

Oksanen J, Blanchet FG, Kindt R, Legendre P, Minchin PR, O'Hara RB, Simpson GL, Solymos P, Henry M, Stevens H, Wagner H (2013) Vegan: community ecology package. R package version 2.0-4. Padisak http://CRAN.R-project. org/package=vegan

Padisak J, Crossetti LO, Naselli-Flores L (2009) Use and misuse in the application of the phytoplankton functional classification: a critical review with updates. Hydrobiologia 621:1-19

Potapova M (2010) Aulacoseira pusilla. In diatoms of the United States. Retrieved January 14, 2012. http:// westerndiatoms.colorado.edu/taxa/species/_pusilla. Accessed on 08 Feb 12

Potapova M, Hamilton PB (2007) Morphological and variation within the Achnanthidium minutissimum (Bacillariophyceae) species complex. J Phycol 43:561-575

R Core Team (2012) R: a language and environment for statistical computing. R Foundation for Statistical Computing, Vienna, Austria. ISBN 3-900051-07-0, http://www.R-project.org/

Reynolds CS (1988) Functional morphology and adaptive strategies of freshwater phytoplankton. In: Sandgren CD (ed) Growth and reproductive strategies of freshwater phytoplankton. Cambridge University Press, Cambridge, pp 388-433

Reynolds CS, Huszar V, Kruk C, Naselli-Flores L, Melo S (2002) Towards a functional classification of the freshwater phytoplankton. J Plank Res 24:417-428

Saros E (2009) Integrating neo- and paleolimnological approaches to refine interpretations of environmental change. J Paleolimnol 41:243-252

Saros JE, Anderson NJ (2014) The ecology of the phytoplanktonic diatom Cyclotella and its implications for global environmental change studies. Biol Rev. doi:10.1111/brv. 12120

Schroeder LA, Martin SC, Poudel A (2009) Factors contributing to cucumber odor in a northern USA reservoir. Lake Reserv Manag 23:323-335

Serieyssol CA, Edlund MB, Kallemeyn LW (2009) Impacts of settlement, damming, and hydromanagement in two boreal lakes: a comparative paleolimnological study. J Paleolimnol 42:497-513

Shotbolt LA, Thomas AD, Hutchinson SM (2005) The use of reservoir sediments as environmental archives of catchment inputs and atmospheric pollution. Prog Phys Geog 29:337-361

Shotbolt LA, Hutchinson SM, Thomas AD (2006) Sediment stratigraphy and heavy metal fluxes to reservoirs in the southern Pennine uplands, UK. J Paleolimnol 35:305-322 
Smol JP (1992) Paleolimnology: an important tool for effective ecosystem management. J Aquat Ecosyst Health 1:49-58

Smol JP (2008) Pollution of Lakes and Rivers: a paleoenvironmental perspective, 2nd edn. Blackwell, Oxford

Soballe DM, Kimmel BL (1987) A large-scale comparison of factors influencing phytoplankton abundance in rivers, lakes, and impoundments. Ecology 68:1943-1954

Stoermer EF, Smol JP (eds) (1999) The diatoms: application for the environmental and earth sciences. Cambridge University Press, Cambridge

Straškraba M, Tundisi JG (1999) Reservoir ecosystem functioning: theory and application. In: Tundisi JG, Straškraba M (eds) Theoretical reservoir ecology and its applications. International Institute of Ecology. Brazilian Academy of Sciences and Backhuys Publishers, Brazil, pp 565-597

Tilman D, Kilham SS (1976) Phosphate and silicate growth and uptake kinetics of diatoms Asterionella formosa and $C y$ clotella meneghiniana in batch and semicontinous culture. J Phycol 12:375-383

USDA NASS (2006) http://www.nass.usda.gov/Quick_Stats/. Accessed on 8 Aug 2006
USEPA (1971) Feasibility study: upper meander creek mine drainage abatement project. Stanley Consultants, Cleveland

van Dam H, Mertens A, Sinkeldam J (1994) A coded checklist and ecological indicator values of freshwater diatoms from the Netherlands. J Aquat Ecol 28:117-133

Winston B, Hausmann S, Escobar J, Kenney WF (2014) A sediment record of trophic stage change in an Arkansas (USA) reservoir. J Paleolimnol 51:393-403

Wolfe AP, Baron JS, Cornett RJ (2001) Anthropogenic nitrogen deposition induces rapid ecological change in alpine lakes of the Colorado front range (USA). J Paleolimnol 25:1-7

Wolin JA, Stoermer EF (2005) Response of a Lake Michigan coastal lake to anthropogenic catchment disturbance. J Paleolimnol 33:73-94

Woodridge J, Davies H, Blake W, Fyfe R (2014) Recent environmental change in an upland reservoir catchment: a paleolimnological perspective. J Paleolimnol 52:229-244 